\title{
TROPOSPHERIC RADIO REFRACTIVITY OVER THREE RADIOSONDE STATIONS IN NIGERIA
}

\author{
B. ADEYEMI \\ Department of Physics, Federal University of Technology, P.M.B.704 Akure, Nigeria.
}

(Submitted: 30 March 2004; Accepted: 31 October 2004)

\begin{abstract}
The annual variations of radio refractivity parameter within the first $10 \mathrm{~km}$ of the troposphere are presented for three radiosonde stations in Nigeria, viz: Oshodi, a coastal area in the southwest, Minna, a middle belt Savannah region and Kano, a sub-Sahelian region to the north. Results have shown that the variations in each zone and at the different atmospheric levels are influenced by the north-south movement of the Inter-Tropical Discontinuity (ITD). Correlation coefficients between the combination of surface radio refractivity $\left(N_{s}\right)$, and any of lower level refractivity $\left(N_{t}\right)$, the upper level refractivity $\left(N_{l}\right)$, and the total refractivity for the entire column $\left(N_{7}\right)$, have been found to be more than 0.70 .

Using an analysis of variance (ANOVA) technique on the upper air climatological data spanning over a decade, an empirical relationship of the form $N=\alpha\left(N_{S}\right)^{\mathrm{b}}$ ( $\alpha$, b constants) has been established between refractivity aloft and its surface value, $N_{s}$, over the three stations in Nigeria. For instance, values of $\alpha$ and $b$ for the refractivity parameters at Oshodi are 0.9308 and 0.9963 for $N_{l,} 37.812$ and 0.3547 for $N_{U}, 3.1955$ and 0.7820 for $N_{T}$ respectively. Comparison made between the model and the actual values using the Kolmogorov Smirnov test have shown that the models for the three stations performed well during the dry season.
\end{abstract}

Keywords: Radio refractivity, troposphere, radiosonde stations, inter-tropical discontinuity, Savannah.

\section{Introduction}

The physical properties of the atmosphere determining the peculiarities of radiowave propagation are characterized by value of the radio refractive index. The radio refractive index of air, $n$, is slightly greater than unity, hence it is convenient to replace ' $n$ ' with the radio refractivity $N$ defined by $N=(n-1) \times 10^{6}$. Thus the radio refractivity of air $N$ is an important parameter considered in the propagation of radiowaves through the atmosphere. Its space-time variation results in scattering, sub refraction, super refraction, ducting, and absorption phenomena. The vertical profile simulations of the refractive index of the troposphere have gone a long way in providing useful explanations for the various radiowave propagation mechanisms (Batueva et al., 1998).

Radiowaves with wavelengths shorter than about 10 m (Kolawole and Owonubi, 1982) are severely attenuated in the troposphere while waves with longer wavelengths can propagate through the troposphere with little attenuation. Therefore a radio engineer facing the task of designing a radio circuitry for the terrestrial broadcast has to give special consideration to the expected behaviour of the refractivity value along the propagation trajectory. Much more also, that the communication links operating at frequencies within the VHF up to microwaves depend much on the propagation conditions of the earth's troposphere, since the geometry of the path followed by the radio waves depends mostly on the vertical distribution of the atmospheric refractive index (Owolabi and Ajayi, 1979). Many of the oceanic coastal areas of the world are subject to land-sea circulation patterns that lead to spectacular refractive effects at both optical and radio frequencies. These effects often results from the contrast between the temperature and humidity at the sea surface and the temperature and humidity of the overlying air whose origin was over adjacent land areas (Richter, 1979). The refraction and ducting resulting form the air-sea contrast in refractive index has usually been discussed under the name 'evaporation duct'. Gossard (1978) gave a good account of the mechanism of generation of the evaporation duct, and some analytical approaches to its formation in the coastlines. Yasuo and Kenichi (1982) in their work on single mode condition of optical fibres highlighted that to calculate the cut off frequencies of the transverse electric field $\left(\mathrm{TE}_{01}\right)$, transverse magnetic field $\left(\mathrm{TM}_{01}\right)$ and transverse electromagnetic field ( $\left.\mathrm{HE}_{21} / \mathrm{TEM}\right)$ modes which are important parameters in the designing of single mode fibres, the refractive index distribution in the core must be known. 
There is a general dearth of information on radio propagation measurements in the tropical countries of the world, therefore contributions based on the interpretation of few available data should play significant role in determining the propagation characteristics and hence, be of interest to the engineers involved in designing microwave radio links, terrestrial or satellite-based for the tropics. Bean and Thayer (1959) first investigated the correlation between the monthly means of surface refractivity $N_{\mathrm{s}}$ and the monthly means of the refractivity decrease in the first kilometre above the ground, $\Delta N$. The expression relating both averages is given by:

$$
-\Delta N=\alpha \exp \left(\beta \cdot N_{\mathrm{s}}\right)
$$

where $\alpha$ and $\beta$ are constants that are characteristic for each region.

Pickard and Stetson (1950) established that a correlation existed between the transmission loss and the surface refractivity value, $N_{\mathrm{s}}$ According to Lane (1961), this is only true when there is a good correlation between the refractivity decrease in the first kilometre $\Delta N$ and $N_{\mathrm{S}}$. Studies by Kolawole (1983), Owonubi (1992), Babalola (1998) and Willoughby et al. (2002), have shown that $N_{\mathrm{S}}$ and $\Delta N$ are very well correlated in the African region.

In the study of refractive index turbulence, Wyngaard and Le Mone (1980), Fairall (1987) and Wyngaard et al. (2001) have observed that within the atmospheric boundary layer (ABL), the atmospheric refractive index fluctuates chaotically in time and in all three spatial directions. That near the top of the convective boundary layer, the values of the structure function parameters (which include temperature, water vapour and relative humidity) typically depart from those of the mixed layer forms and increase sharply to peak values before decreasing again at greater heights. Over Nigeria, the vertical structure of the atmospheric refractive index has been studied by Kolawole (1981) using radiosonde data from three stations. Willoughby et al. (1995) and Babalola (1996) studied the vertical gradient of refractivity in Nigeria predicting the frequency of occurrence of super-refraction and ducting at the different regions of the country. Batueva et al. (1998) and Zhamsuyeva and Zayakhanov (1998) have also studied the vertical distributions of this parameter in Russia. The objective of this paper is to study the space-time distribution of the monthly mean refractivity at different columns of the troposphere over three radiosonde stations in Nigeria with a view to establishing intra-layer relationship between surface, low-level and upper-level of this meteorological quantity. The results obtained were then subjected to the Kolmogorov-Smirnov (KS) test.

\section{Data}

The upper air data used in the computations reported in this paper were obtained from the archives of the Department of the Meteorological Services, Federal Ministry of Aviation at Oshodi in Lagos, Nigeria. The data obtained for the period 1975-1990 were those used in making the computations for the three stations as shown in Table 1.

Table 1: Geographic and Climatic characteristics of the stations

\begin{tabular}{|l|r|r|r|l|}
\hline Station & Latitude & Longitude & $\begin{array}{l}\text { Station } \\
\text { Elevation (m) }\end{array}$ & Climate \\
\hline Lagos/Oshodi & $6^{0} 28 \mathrm{~N}$ & $3^{0} 28^{\prime} \mathrm{E}$ & 19 & Humid \\
\hline Minna & $9^{0} 37 \mathrm{~N}$ & $6^{0} 30^{\circ} \mathrm{E}$ & 249 & Partially humid \\
\hline Kano & $12^{0} 02^{\circ} \mathrm{N}$ & $8^{0} 30^{\circ} \mathrm{E}$ & 480 & Semi-arid \\
\hline
\end{tabular}

Table 2: Values of the best fit parameters $\alpha$, and $b$ in the regression equation of $N_{L}$ on $N_{s}, N_{U}$ on $N_{s}$, and $N_{T}$ on $N_{s}$

\begin{tabular}{|c|c|c|c|c|c|c|c|c|c|c|c|c|c|c|c|c|}
\hline \multirow{2}{*}{ Station } & \multirow{2}{*}{$N$} & \multicolumn{5}{|c|}{$N_{L}=\alpha\left(N_{s}\right)^{b}$} & \multicolumn{5}{|c|}{$\mathrm{N}_{\mathrm{U}}=\alpha\left(\mathrm{N}_{\mathrm{S}}\right)^{\mathrm{b}}$} & \multicolumn{5}{|c|}{$\mathrm{N}_{\mathrm{T}}=\alpha\left(\mathrm{N}_{\mathrm{S}}\right)^{\mathrm{b}}$} \\
\hline & & $\alpha$ & b & $\mathrm{r}$ & $\mathrm{CV}$ & $\begin{array}{l}\text { p- } \\
\text { value }\end{array}$ & $\alpha$ & $\mathrm{b}$ & $\mathrm{r}$ & $\mathrm{CV}$ & $\begin{array}{l}\mathrm{p}- \\
\text { value }\end{array}$ & $\alpha$ & $b$ & $r$ & $\mathrm{CV}$ & $\begin{array}{l}\mathrm{p}- \\
\text { value }\end{array}$ \\
\hline Oshodi & 12 & 0.93 & 0.99 & 0.77 & 59.5 & 0.003 & 37.81 & 0.355 & 0.57 & 32.2 & 0.050 & 3.20 & 0.78 & 0.73 & 53.4 & 0.007 \\
\hline Minna & 12 & 5.15 & 0.71 & 0.99 & 99.9 & 0.000 & 179.2 & 0.093 & 0.99 & 99.6 & 0.001 & 24.8 & 0.43 & 0.99 & 99.9 & 0.000 \\
\hline Kano & 12 & 6.28 & 0.68 & 0.99 & 99.9 & 0.000 & 170.0 & 0.104 & 0.92 & 83.1 & 0.000 & 23.9 & 0.44 & 0.99 & 98.9 & 0.000 \\
\hline
\end{tabular}




\subsection{Data analysis technique}

The radio refractivity of air, $N$, for frequencies up to $100 \mathrm{GHz}$ is generally expressed as

$$
N=77.6 \frac{P}{T}+3.75 \times 10^{5} \frac{e}{T^{2}}
$$

where $P$ is the atmospheric pressure in $\mathrm{hPa}, T$ is the temperature in Kelvin and $e$ is the vapour pressure in hPa (Bean, 1966; Adeyefa, 1995). The first term on the right hand side of Eq. 2 represents the dry component $\left(N_{d r y}\right)$ and the second term is the wet component $\left(N_{w e r}^{d r y}\right)$. While $N_{d r y}$ contributes about $66 \%$ of the total value of $N, N_{\text {wet }}$ is mainly responsible for its variability.

The $N_{d r y}$ and $N_{w e t}$ term components from Eq. 2 are defined as

$$
N_{d r y}=77.6 \frac{P}{T} ; \quad N_{w e t}=3.75 \times 10^{5} \frac{e}{T^{2}}
$$

The analysis technique adopted here is identical to that in Aro (1975) where refractivity values were calculated for three layers: surface $-3 \mathrm{~km}, 3-10$ $\mathrm{km}$ and surface $-10 \mathrm{~km}$ to be known as $N_{L}$ (refractivity at the lower atmosphere), $N_{u}$ (refractivity at the upper atmosphere and $N_{f}$ (refractivity at the first $10 \mathrm{~km}$ of the atmosphere) respectively. $N$ values at the surface and at each level were calculated using Eq.2. After this, we obtained for each station correlations of $\left(\ln N_{s}, \ln N_{l}\right),\left(\ln N_{s}, \ln N_{l}\right)$ and $(\ln$ $N_{s}, \ln N_{\text {r) }}$. The correlation values for the above stated combinations i.e. between the surface refractivity and any of the columnar refractivity have been found to be more than 0.7 (see Table 2). An analysis of variance (ANOVA) table (not shown) was worked out for each station taking into consideration the associated $F$-ratios and the null hypothesis tests. This then suggests a regression relation of the form,

$$
\ln N=a+b \ln N_{s}
$$

Hence, we obtain, from Eq. 4

$$
N=\alpha\left(N_{s s}\right)^{b}
$$

where $\alpha=e^{a}$. In Eqs. 4 and 5, $N$ can be replaced by $N_{l}, N_{l,}$ and $N_{T}$ and the corresponding parameters $\alpha$ and $b$ evaluated.

Next, $N$ values at each level are calculated using the developed empirical relations. These were then examined using the KS test (Kendall and Stuart,
1979; Adedokun, 1989) in order to determine whether or not any agreement exists between the actual distribution function $F_{N}(x)$ and each modelgenerated series $F_{C}(x)$. As in Adedokun (1986), the maximum deviation between $F_{N}(x)$ and $F_{C}(x)$ is:

$$
D_{N}=\max \left|F_{N}(x)-F_{C}(x)\right|
$$

where $x$ is ordered such that:

$$
0 \leq x_{1} \leq x_{2} \leq x_{3} \ldots \ldots \ldots \ldots \ldots \ldots \ldots
$$

for $N$ observations

If $\Omega$ is number of values $\leq x, F_{N}(x)=\Omega / \sqrt{N}$

According to Kendall and Stuart (1979), critical values of $D_{N}$ for 5 percent significant level is:

$$
D_{N}\left(\alpha^{\prime}=0.05\right)=1.3581 / \sqrt{N}
$$

Agreement exists between $F_{N}(x)$ and $F_{C}(x)$ if $D_{N} \leq D_{N}$ $\left(\alpha^{\prime}=0.05\right)$, for the significant level under consideration.

\section{Results and Discussions}

\subsection{Mean Columr Refractivity}

Figs. 1, 2 and 3 show the monthly means of the columnar refractivity at the three stations, and its component parameters which include, the dry, $N_{d r y}$, the wet, $N_{\text {wet }}$ and the surface, $N_{S}$ terms. Oshodi, (see Fig. 1a-c) being a coastal area, displays uniform and high values of all the columnar refractivity parameters. Here, surface $\left(N_{s}\right)$ values are higher, all the year round, than those of lower $\left(N_{L}\right)$ and upper columns $\left(N_{t)}\right)$ of the atmosphere. The refractivity values for the entire column $N_{T}$ is constantly lower than those of the surface all the year round. $N_{s}$ varies from about 350-400 N-units; $N_{L}$ varies from about 330-350 N-units, $N_{u}$, about $300-310 \mathrm{~N}$-units, and $N_{p}$, from about $320-350 \mathrm{~N}$-units.

At Minna, an inland station (see Fig. 2a-c) $N_{S}, N_{L}$, $N_{U}$ and $N_{T}$ are closely related in values during the dry months of November to March; while during the rainy months of April to October, both $N_{L}$ and $N_{T}$ follow closely $N_{s}$ and attain high values lasting between May and October. On the other hand $N_{U}$ remained constant having values not quite different from its dry season values. The variations observed in $N_{L}, N_{T}$ and $N_{S}$, during the rainy season, may be because the period is characterized by intense rainfall 


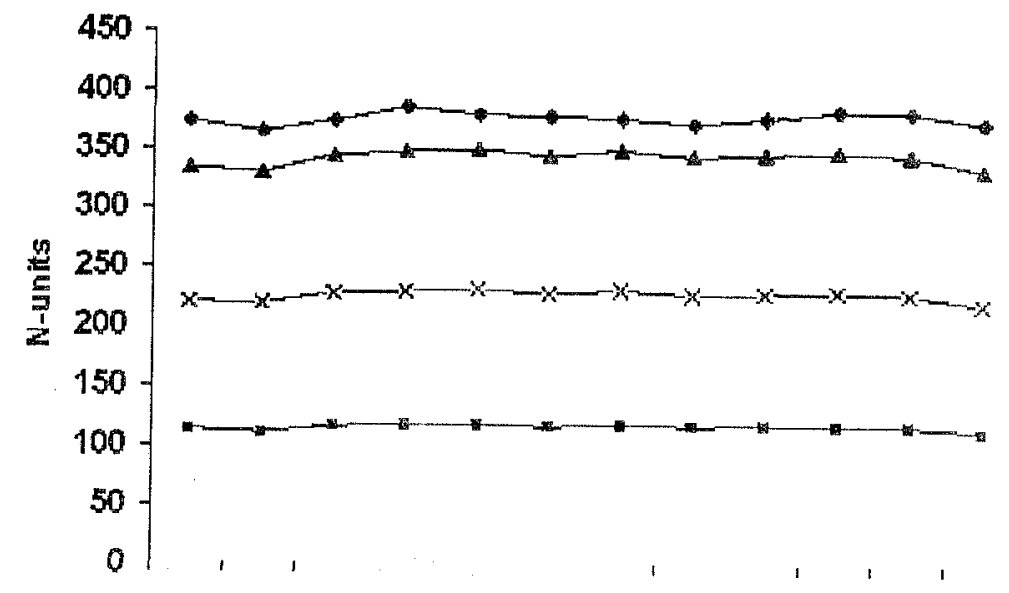

Jan Feb Mar Apr May Jun Jul Aug Sep Oct Nov Dec

a) MONTHS

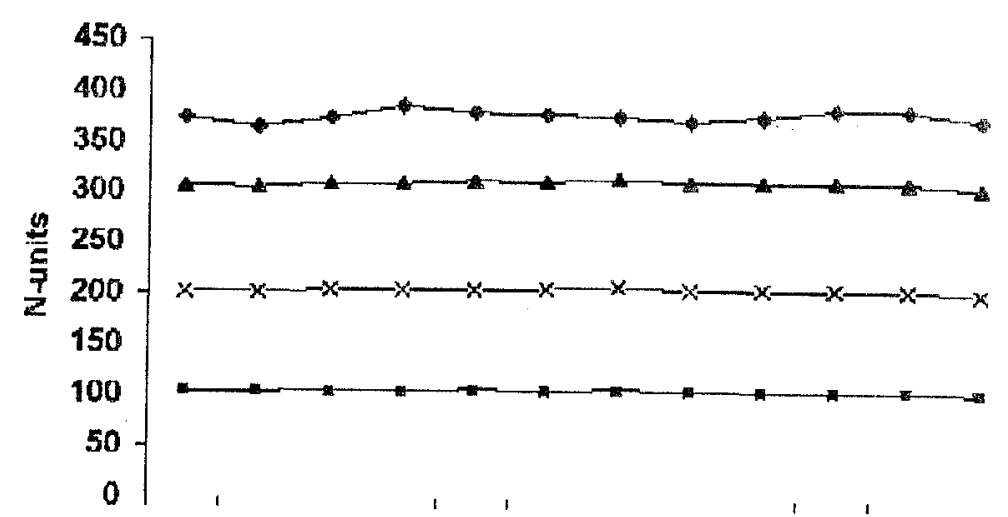

Jan Feb Mar Apr May Jun Jul Aug Sep Oct Nov Dec b) MONTHS

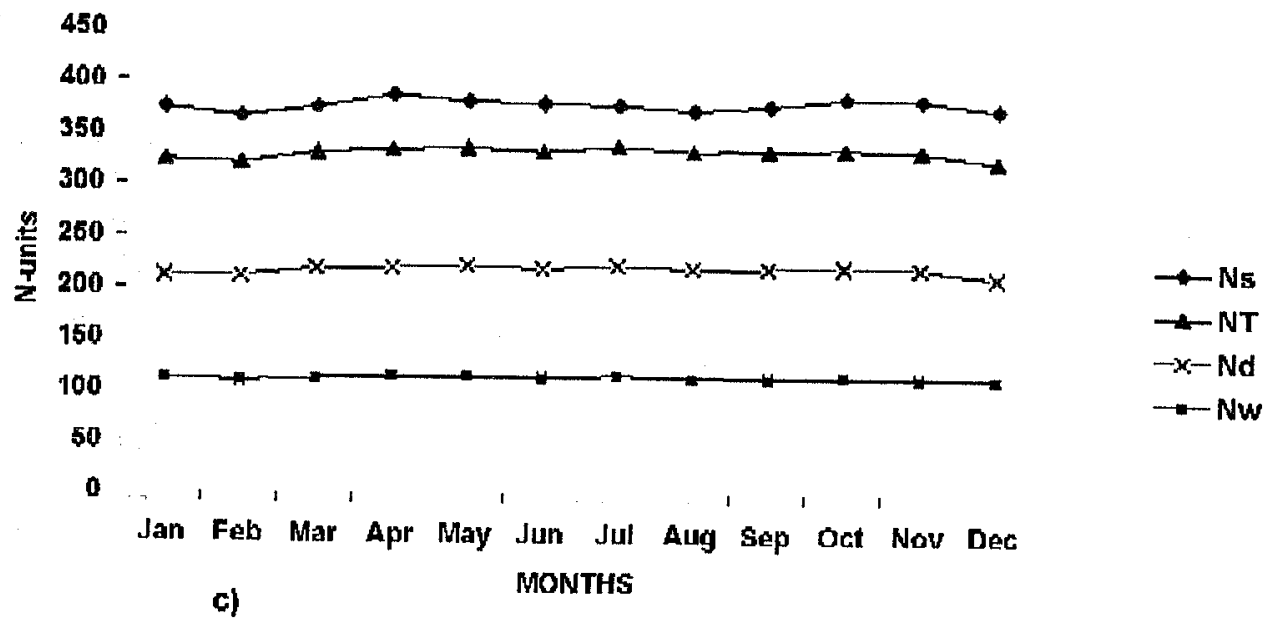

Fig. 1. Monthly variations of mean refractivity at different atmospheric levels and related parameters at Oshodi. 


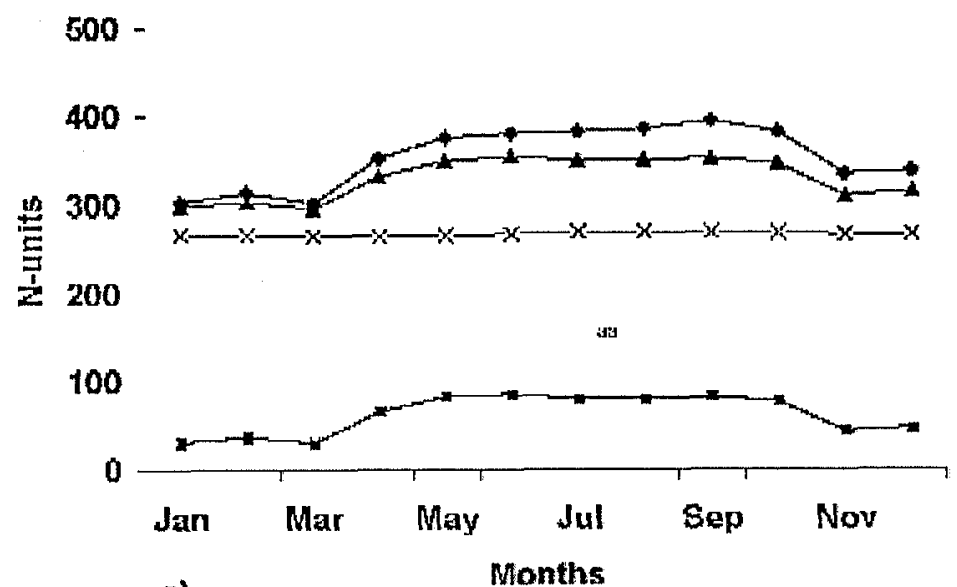

a)

$$
\begin{aligned}
& -N s \\
& --N L \\
& -x-N d \\
& \rightarrow-N w
\end{aligned}
$$

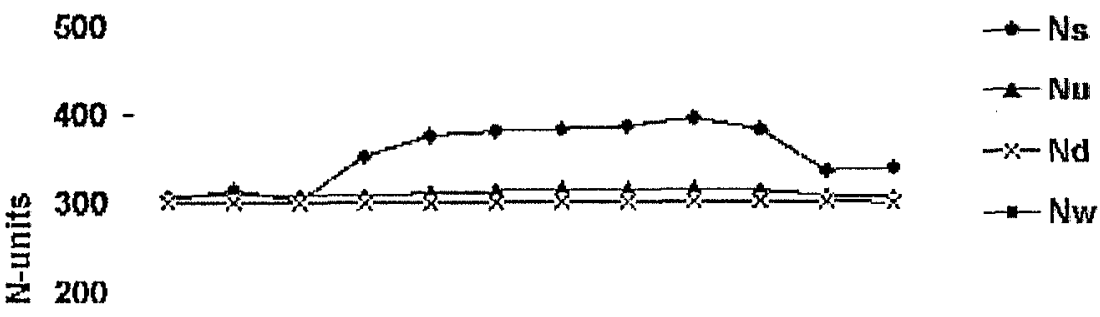

100

b)
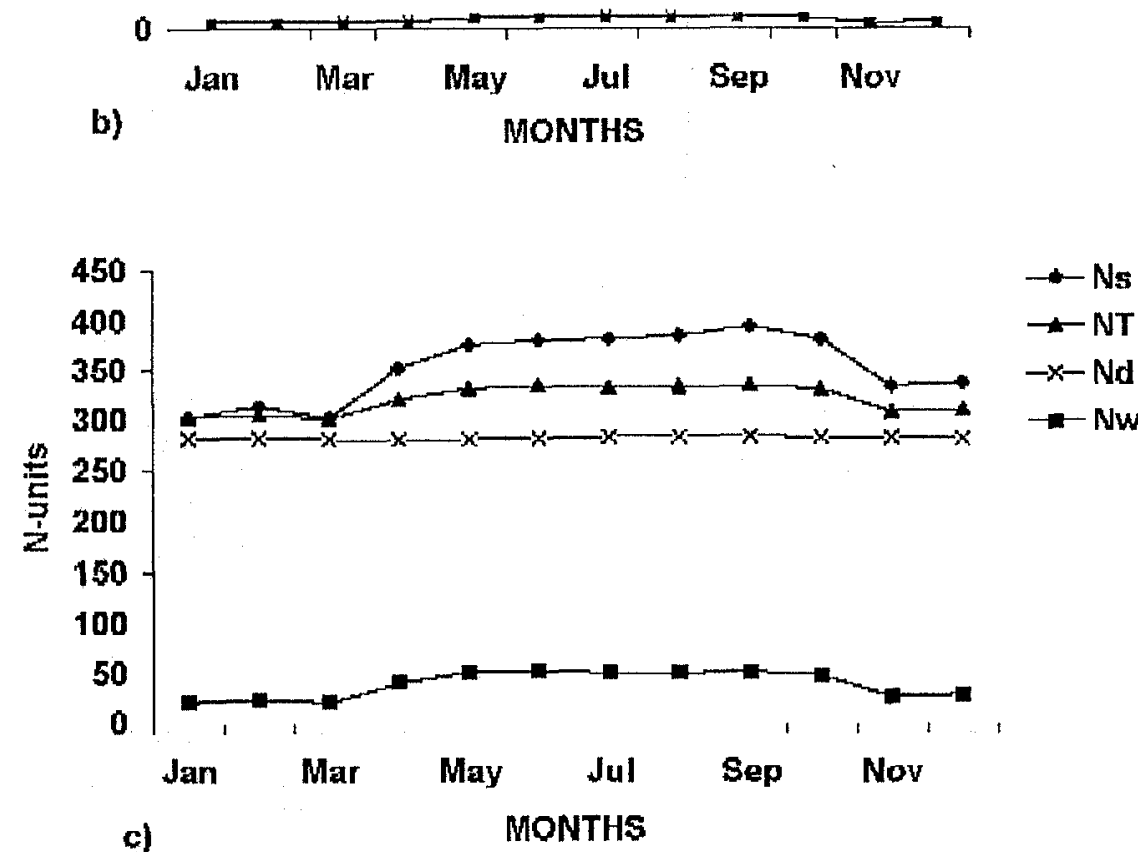

Fig. 2. Monthly variations of mean refractivity at different atmospheric levels and related parameters at Minna. 


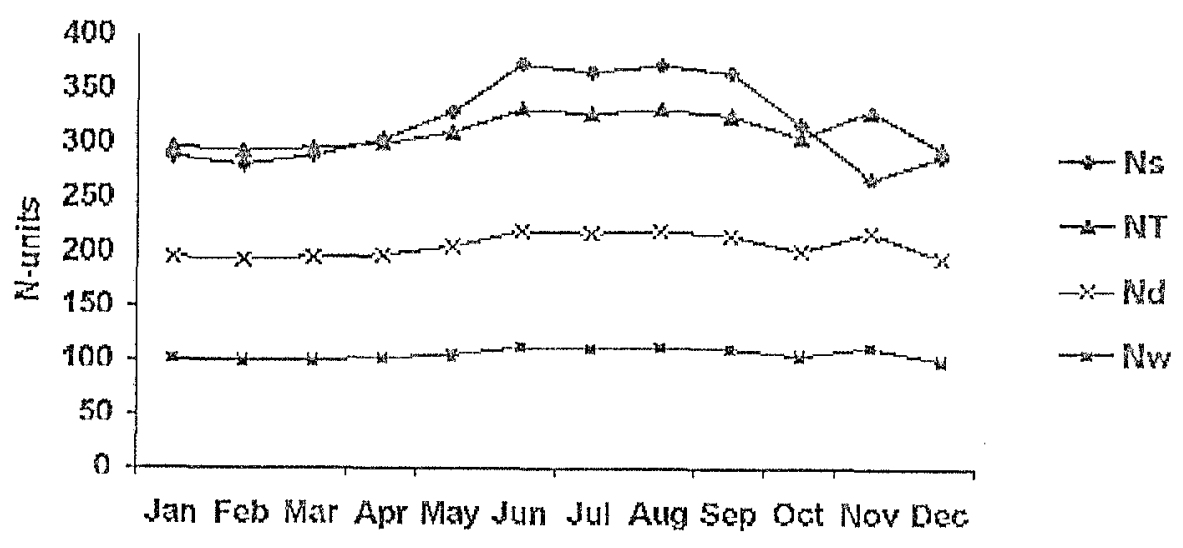

a) MONTHS
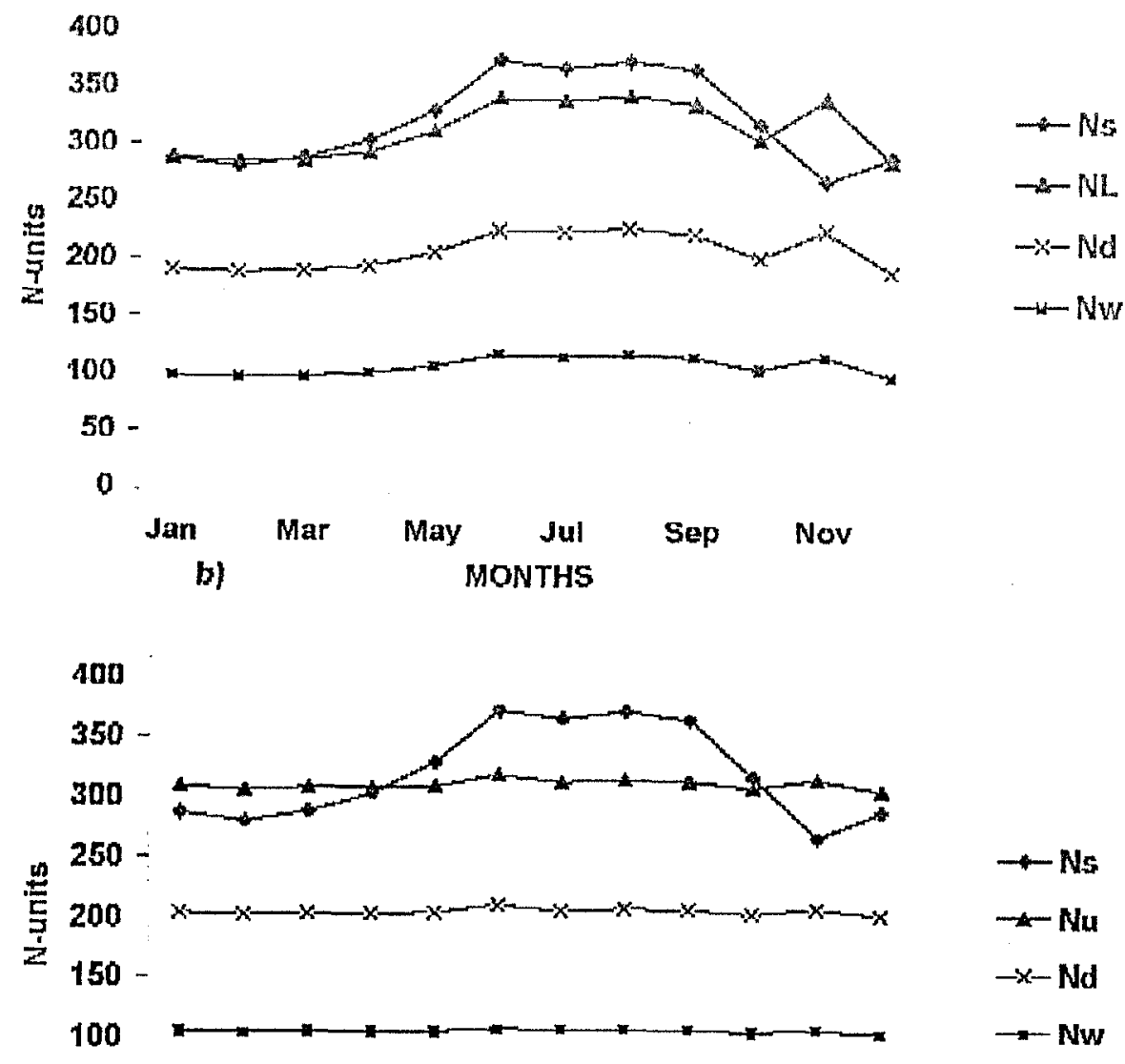

50 -

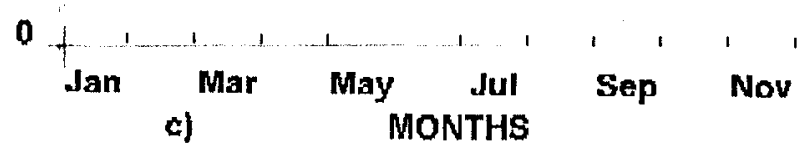

Fig. 3. Monthly variations of mean refractivity at different atmospheric levels and related parameters at Kano. 
which keeps the atmosphere in constant supply of water vapour. The refractivity at the upper level, $\left(N_{U}\right)$, is not as high as $N_{L}$ and $N_{T}$ in this station during the rainy period. This may be attributed to the fact that in the higher layers, perpetual accumulation of water vapour is prevented by cloud formation and prevailing winds. Hence low values of $N$ results (Aro, 1975).

At Kano, a sub-sahellian station, (see Fig. 3a-c), $N_{l}$ ,$N_{U}$ and $N_{T}$ display similar seasonal pattern. During the dry months of November to April, their values compare well with that of $\mathrm{N}_{\mathrm{s}}$, whereas during the rainy months, $N_{U}$ displays higher values than them all. $N_{u}$ values here also are uniform throughout the year. All except $N_{l p}$ display higher values during the rainy season than the dry season period. This shows the dependency of refractivity on water vapour.

At all the stations, and for all the atmospheric levels, the dry $\left(N_{d r y}\right)$ term is the dominant contributor to refractivity while the wet $\left(N_{\text {wel }}\right)$ term is responsible for the variations observed in refractivity. This is in conformity with the result obtained by Adeyemi (1992), Adeyefa (1995) and Willoughby et al. (2002) where in each case it was highlighted that the dry term $\left(N_{d r y}\right)$ contributes about $60-70 \%$ to refractivity irrespective of the season.

Table 2 shows the best fit parameters $\alpha$, b obtained for each station, the coefficient of variation (CV) and the probability p-value at which the null hypothesis was either accepted or rejected. Observing Table 2, a high degree of relationship exists between $N_{L}$ and $N_{S}$ (see Table $2 \mathrm{a}$ ), $N_{U}$ and $N_{S}$ (see Table 2b), $N_{T}$ and $N_{s}$ (see Table 2c). The null hypothesis is rejected at $p<0.05$ for all the cases. Hence for all, null hypothesis is hereby rejected. The coefficient of variation is higher in the midland and Northern zone than in the coastal (Southern) zone of Oshodi, suggesting a higher amount of variation in the more arid zone as is normally expected (Adedokun, 1983). This may be due to strong atmospheric turbidity experienced in the North (McTainsh, 1984). The generally high correlation coefficients in Table 2 are normally typical of monthly mean data (Reitan, 1963). However, this degree of correlation decreases for shorter time (e.g. daily/hourly) data (Bolsenga, 1965).

To verify the reliability of the relations obtained in Table 2 above, we feed in $N_{S}$ (mean of monthly) values obtained for the months of November-March, depicting the dry season period, for the individual stations, to the regression relations. The results are shown in Table 3.

Comparing the actual and calculated values at both season and at different stations as shown in Table 3, the agreements between them is remarkable. As can be observed in the table, Kano, a sub-sahelian station, was well monitored at the three atmospheric levels considered by the models, because the residuals are low. Refractivity at the three levels were fairly well monitored at Oshodi (residuals are fairly high). At Minna, a midland station, the low level refractivity $N_{L}$ was well monitored (low residuals), the upper level, fairly well monitored (fairly high residuals), and $N_{T}$ (refractivity for the total column was badly monitored by the model during the rainy season of April to October (residuals are high). During the dry season, $N_{\eta}$, at Minna, was fairly well monitored by the proposed model. The observation at Minna which showed least agreement at the upper level during the rainy season may be because of its nearness to ITD (Adedokun, 1983) for that time of the year. Also, Minna, being closer to Niger River, might experience local variability with high water vapour aloft than expected from low level observations. The low agreement observed in Oshodi could be because Lagos is a coastal station.

\subsection{The Kolmogorov-Smirnov (KS) test:}

As have been defined earlier, the KS test is used to determine whether agreement exists between the actual and the calculated values. Applying this test to the low-level, $N_{L}$ upper-level $N_{U}$ and total refractivity for the column $N_{\eta}$, the following results were obtained as shown in Table 4.

Table 4 indicates that the model formulated for refractivity at low level, $N_{L}$, refractivity at upper level, $N_{U}$ and total refractivity for the column $N_{7}$ performed well only in Kano. At Oshodi and Minna, none of the models performed well. Oshodi is a coastal station, hence oceanic (sea-breeze) effects may be responsible for this situation. Minna on the other hand is a midland station, but this station is located on the wet terrain of the river Niger. Therefore, seabreeze effect may also be responsible for its own situation too.

For effective monitoring of the seasonal changes, we have looked closely at the performance of the models over each of the stations during the dry season (November-March) and the rainy season (April-October), as shown in Table 5.

Performance of the Models during the Dry Season:

(i) The individual model for $N_{L}$ (refractivity at the lower level of the atmosphere) for the different stations, performed well at the stations.

(ii) The individual model for $N_{U}$ (refractivity at the upper atmosphere), for the different stations performed well at all the stations. 
Table 3: Application of the proposed model for each of the stations.

\begin{tabular}{|c|c|c|c|c|c|c|c|c|}
\hline \multirow{2}{*}{$\begin{array}{l}\text { (a) Station } \\
\text { Oshodi }\end{array}$} & \multicolumn{8}{|c|}{ Equations: $\mathrm{N}_{\mathrm{L}}=0.9308 \mathrm{~N}_{\mathrm{S}}{ }^{0.9963} ; \mathrm{N}_{\mathrm{U}}=37.812 \mathrm{~N}_{\mathrm{S}}^{0.3547} ; \mathrm{N}_{\mathrm{T}}=3.1955 \mathrm{~N}_{\mathrm{S}}^{0.782}$} \\
\hline & $N$ & $\mathrm{~N}_{\mathrm{S}}$ & $\begin{array}{r}1 \\
\text { actual } \\
\end{array}$ & calculated & actual & $\begin{array}{l}\mathrm{N}_{U} \\
\text { calculated }\end{array}$ & $\begin{array}{l}\mathrm{N}_{\mathrm{T}} \\
\text { actual }\end{array}$ & calculated \\
\hline $\begin{array}{l}\text { Dry } \\
\text { season }\end{array}$ & 5 & 374 & 338 & 340.6 & 308 & 309.2 & 326 & 328.5 \\
\hline $\begin{array}{l}\text { Rainy } \\
\text { season }\end{array}$ & 7 & 380 & 348 & 345.6 & 312. & 310.8 & 334 & 332.3 \\
\hline
\end{tabular}

\begin{tabular}{|c|c|c|c|c|c|c|c|c|}
\hline (b) Station & Equations & \multicolumn{7}{|c|}{$\mathrm{N}_{\mathrm{L}}=5.149 \mathrm{~N}_{\mathrm{S}}{ }^{0.7089} ; \mathrm{N}_{\mathrm{U}}=179.2 \mathrm{~N}_{\mathrm{S}}{ }^{0.0932} \mathrm{~N}_{\mathrm{T}} 24.821 ; \mathrm{N}_{\mathrm{S}}^{0.436 \mathrm{I}}$} \\
\hline Minna & $\mathrm{N}$ & $\mathrm{N}_{\mathrm{S}}$ & $\begin{array}{r}N \\
\text { actual } \\
\end{array}$ & calculated & actual & $\begin{array}{l}\mathrm{Ju} \\
\text { calculated }\end{array}$ & $\begin{array}{l}\mathrm{N}_{\mathrm{T}} \\
\text { actual }\end{array}$ & calculated \\
\hline $\begin{array}{l}\text { Dry } \\
\text { season }\end{array}$ & 5 & 381.7 & 304.2 & 306.5 & 306.3 & 306.7 & 305.1 & 306.6 \\
\hline $\begin{array}{l}\text { Rainy } \\
\text { Season }\end{array}$ & 7 & 378.2 & 346.8 & 346.0 & 311.7 & 311.6 & 330.9 & 330.3 \\
\hline
\end{tabular}

\begin{tabular}{|c|c|c|c|c|c|c|c|c|}
\hline (c) Station & Equations & \multicolumn{7}{|c|}{$\mathrm{N}_{\mathrm{L}}=6.276 \mathrm{~N}_{\mathrm{S}}{ }^{0.6746} ; \mathrm{N}_{\mathrm{U}}=169.96 \mathrm{~N}_{\mathrm{S}}{ }^{0.1043} ; \mathrm{N}_{\mathrm{T}}=23.934 \mathrm{~N}_{\mathrm{S}}{ }^{0.4433}$} \\
\hline Kano & $\mathrm{N}$ & $\mathrm{N}_{\mathrm{S}}$ & actu & calculated & actual & calculated & $\begin{array}{l}\mathrm{N}_{\mathrm{T}} \\
\text { actual }\end{array}$ & calculated \\
\hline $\begin{array}{l}\text { Dry } \\
\text { season }\end{array}$ & 5 & 302 & 297 & $295.6^{\circ}$ & 309 & 308.3 & 302 & 3009 \\
\hline $\begin{array}{l}\text { Rainy } \\
\text { Season }\end{array}$ & 7 & 346 & 325 & $\$ 324.0$ & 312. & 312.7 & 316 & 319.6 \\
\hline
\end{tabular}

Table 4: Results of KS test on actual and model $N_{L}, N_{U}$ and $N_{T}$ values.

\begin{tabular}{|l|l|l|l|l|}
\hline Stations & & $\mathrm{N}_{\mathrm{L}} \ldots$ & $\mathrm{N}_{\mathrm{U}}$ & $\mathrm{N}_{\mathrm{T}}$ \\
\hline & $\begin{array}{l}\mathrm{D}_{\mathrm{N}} \\
(\alpha=0.05)\end{array}$ & $\mathrm{D}_{\mathrm{N}}$ & $\mathrm{D}_{\mathrm{N}}$ & $\mathrm{D}_{\mathrm{N}}$ \\
\hline Oshodi & 0.392 & 0.559 & 0.411 & 0.538 \\
\hline Minna & 0.392 & 0.584 & 1.888 & 1.873 \\
\hline Kano & 0.392 & $0.343^{*}$ & $0.347^{*}$ & $0.211^{*}$ \\
\hline
\end{tabular}

Association exists between actual values and model values at 5 percent significant level.

Table 5: Results of the KS test on actual and model during the dry and the rainy seasons

\begin{tabular}{|c|c|c|c|c|c|c|c|c|}
\hline \multirow[t]{2}{*}{ Stations } & \multirow[t]{2}{*}{$\begin{array}{l}\mathrm{D}_{\mathrm{N}} \\
(\alpha=0.05)\end{array}$} & \multicolumn{3}{|c|}{$\begin{array}{l}\text { Values of } D_{N} \text { for various refractivity } \\
\text { parameters during the dry season. }\end{array}$} & \multirow[t]{2}{*}{$\begin{array}{l}\mathrm{D}_{\mathrm{N}} \\
(\alpha=0.05)\end{array}$} & \multicolumn{3}{|c|}{$\begin{array}{l}\text { Values of } D_{N} \text { for various refractivity } \\
\text { parameters during the rainy season }\end{array}$} \\
\hline & & $D_{N}$ for $N_{L}$ & $\mathrm{D}_{\mathrm{N}}$ for $\mathrm{N}_{\mathrm{U}}$ & $\mathrm{D}_{\mathrm{N}}$ for $\mathrm{N}_{\mathrm{T}}$ & & $D_{N}$ for $N_{L}$ & $\mathrm{D}_{\mathrm{N}}$ for $\mathrm{N}_{\mathrm{U}}$ & $\mathrm{D}_{\mathrm{N}}$ for $\mathrm{N}_{\mathrm{T}}$ \\
\hline Oshodi & 0.607 & $0.548^{*}$ & $0.266^{*}$ & $0.458^{*}$ & 0.513 & 0.559 & $0.411^{*}$ & 0.538 \\
\hline Minna & 0.607 & $0.583^{*}$ & $1.360^{*}$ & $1.808^{*}$ & 0.513 & $0.513^{*}$ & $1 . \overline{888}$ & 1.873 \\
\hline Kano & 0.607 & $0.343^{*}$ & $0.192^{*}$ & $0.142^{*}$ & 0.513 & $0.271^{*}$ & $0.317^{*}$ & $0.241^{*}$ \\
\hline
\end{tabular}


(iii)

The models for $N_{r}$ performed well at two of the stations, which are Oshodi and Kano.

These show that the models performed well during the dry season at all the stations except Minna, where the $N_{1}$ model could not satisfy it. From Table 3 , it could be observed that, during this period of the year, overestimation of refractivity parameters persists in two of the stations, which are Oshodi and Minna whereas at Kano underestimation occurred. The observations at Oshodi and Minna could be likened to the influence of sea breeze from the ocean and from Niger River respectively. This gives the surface additional moistening giving rise to larger values of atmospheric water vapour than observed. Whereas at Kano, a sub-Sahelian station, the region is covered during the dry season by the Saharan dust plume (Kalu, 1979) where the maximum concentration occurs at about $1000 \mathrm{~m}$ (900 mbar). Adsorption of water vapour by the dust particulate matter and abnormal daily variation in dew point temperatures typify the dry season. Therefore, humidity at surface may not well represent the humidity aloft. This results in underestimation of the refractivity parameters at this station during this period.

Performance of the Models during the Rainy Season

$$
\text { Models for } N_{L} \text { performed well at Minna }
$$
and Kano alone.

Models for $N_{U}$ performed well at Oshodi and Kano but not at Minna.

(iii) Models for $N_{T}$ performed well only at Kano. Those for Oshodi and Minna do not perform well.

In general, only Kano record good performances of the models for the various parameters during the rainy season.

The models for Oshodi and Minna tend to underestimate the refractivity parameters during this period, while those of Kano tend to overestimate them (see Table 3). The observations at Oshodi and Minna could be likened to the occurrence of the little dry season (LDS) accounting for the existence of lower water vapour parameter at the surface. Whereas at Kano, the position of the ITD which reaches up to $22-25^{\circ} \mathrm{N}$ in August (Adejokun, 1966; Adedokun 1978) may account for the overestimation observed in the refractivity parameters.

\section{Conclusion}

At Oshodi, a coastal station, higher and uniform values of refractivity parameters are observed throughout the year (see Fig. 1). Mean values of $N_{S}$ ranges between 350 and $400 N$-units, $N_{l}$, between 330 and $350 \mathrm{~N}$-units, $N_{l}$, between 300 and $310 \mathrm{~N}$ - units and $N_{p}$, between 320 and $350 \mathrm{~N}$-units. In the case of Minna and Kano, refractivity parameter values during the dry season are quite lower than those of rainy seasons. In other words, in these stations, lowest values are found in the dry season period. The difference observed between the Southern and the Northern stations in refractivity values may be likened to the fact that the precipitation climatologies of both region differs appreciably (Balogun, 1981; Garbutt et al., 1981).

Using the analysis of variance (ANOVA) technique, a relation of the form

$$
\begin{aligned}
& N_{l}=\alpha N_{S}^{b} \quad(\alpha, b \text { are constants }) \\
& N_{U}=\alpha N_{S}^{b} \\
& N_{T}=\alpha N_{S}^{b}
\end{aligned}
$$

connecting refractivity at lower level of the atmosphere, $\left(N_{l}\right)$ upper level of the atmosphere, $\left(N_{U}\right)$ and total refractivity in the first $10 \mathrm{~km}$ column $\left(N_{T}\right)$ with surface refractivity $\left(N_{S}\right)$ have been established from upper air climatological data observed over Nigeria (see Table 2). These models when used to evaluate, on a monthly basis, refractivity parameter at each atmospheric level yielded an encouraging results in spite of the known physical draw backs inherent in efforts to infer water vapour aloft using surface conditions (Reber and Swope, 1972).

As demonstrated, using Kolmogorov-Smirnov test on the monthly evaluation of the refractivity parameters, the models for the three refractivity columnar parameters performed well at all the stations during the dry season while during the rainy season, only Kano has good record of performance for all parameters, Oshodi has good record only for $\mathrm{N}_{U}$ model and Minna has good record for only $N_{L}$ model. This shows that that the models developed for Kano at all levels performed better in the two seasons in Nigeria than those of Oshodi and Minna. This may be because the fluctuations of the intertropical discontinuity (ITD) have high influence on the atmosphere at Kano than at Oshodi and Minna. Oshodi, a coastal station, and Minna, a station located on the wet terrain of Niger River, are mainly under the influence of water-air interaction mechanisms which are still subject of investigation.

Finally, the poor agreement observed at Oshodi and Minna therefore may be due to the fact that some atmospheric parameters which have high influence on the circulation aloft in the stations were not incorporated into the analysis. A multivariate regressional model which will take care of these would be considered in future along with more case studies. 


\section{REFERENCES}

Adedokun, J.A., 1978. West Africa precipitation and dominant atmospheric mechanisms Arch. Meteorol. Geophysics. Bioklimatol. Ser. A, 27, 289-310.

Adedokun, J.A., 1983. Intra layer/mid tropospheric precipitable water vapour relations and precipitation in West Africa. Arch. Meteorol. Geophysik. Bioklimatol. Ser. $\mathrm{B}, 33,117-130$.

Adedokun, J.A., 1986. On a relationship for estimating precipitable water vapour aloft from surface humidity over West-Africa. Journal of Clinatology. 6, 161-172.

Adedokun, J.A., 1989. Surface humidity and precipitable water vapour linkage over west and central Africa: Further clarification and evaluation of existing models. International Journal of Climatology, 9, 425-433.

Adejokun, J. A., 1966. The three dimensional structure of the inter-tropical discontinuity over Nigeria, Nigeria Meteorological Serv. Note 39, pp. 1-5.

Adeyemi, R.A., 1992. Seasonal and diurnal variations of surface radio refractivity in Akure, south western Nigeria. M.Tech thesis (Unpublished), Department of Physics, Federal University of Technology, Akure, Nigeria.

Adeyemi, B., 1994. Trend in the variations of surface water vapour density in some southern stations in Nigeria 1987-1991. M.Sc. thesis (Unpublished) Department of Physics, University of Ilorin, Nigeria.

Adeyewa, Z. D., 1995. On the Interrelation of the Refractive index structure and the migration of the Intertropical discontinuity during Harmattan. In: Proceedings of the Regional Workshop on Radio Communication in Africa, Ile-lfe.

Aro, T.O., 1975. Analysis of data on surface and tropospheric water vapour. Journal of Atmos. and Terrestrial Physics 38, 565-571.

Babalola, M.T., 1996. Statistics of the radio refractivity gradient in the lower atmosphere in Nigeria. Nig. Journal of Physics 8, 17-20.

Babalola, M.T., 1998. Studies on the vertical model of the radio refractivity in Nigeria. African Journal of Science 2(1), 1-10.

Balogun, E.E., 1981. Seasonal and spatial variations in thunderstorm activity over Nigeria. Weather, 36(7), 192-197.

Batueva, E.V., Darizhapov, D.D. and Tarbazheeva, O.L., 1998. Vertical distributions of radio meteorological parameters of troposphere of far east of Russia. In: Proceedings of the $8^{\text {th }}$ URSI commission F (Triennial Open Symposium). 22-25 September. Aviero, Portugal. pp.196-199.

Bean, B.R., Cahoon, B.A., Samson, C.A. and Thayer, G.D., 1966. A world atlas of atmospheric radio refractivity, ESSA Monograph \# 1, U.S. Department of Commerce, Washington, USA.

Bean, B.R. and Thayer, G.D., 1959. On models of the atmospheric refractive index. In: Proceedings of IRE 47(5), 740-755.

Bolsenga, S.J., 1965. The relationship between total atmospheric water vapour and surface dew point on a mean daily and hourly basis. Journal of Applied Met. 4, 430-432.

Fairall, C.W., 1987. A top down and bottom-up diffusion model of $\mathrm{C}_{\mathrm{T}}{ }^{2}$ and $\mathrm{C}_{\mathrm{Q}}{ }^{2}$ in the entraining convective boundary layer. J. Atmos. Sci. 44, 1009-1017.

Garbutt, O.J., Stern, R.D., Dennett, M.D. and Elston, J., 1981. A comparison of the rainfall climate of eleven places in West Africa using a two-part model for daily rainfall, Arch. Met. Geoph. Biokl. Ser. B 29, 137. 140.

Gossard, E.E., 1978. The height distribution of refractive index structure parameter in an atmosphere being modified by spatial transition at its lower boundary. Radio Science 13, 489-500.

Kalu, A.E., 1979. The African dust plume: its characteristics and propagation across West Africa in winter. In: Saharan Dust, SCOPE 14, (ed. C. Morales). John Wiley and Sons, Chichester. $95 \mathrm{pp}$.

Kendall, M. and Stuart, A., 1979. The Advanced Theory of Statistics, vol. 2 ( $4^{\text {th }}$ edition). Charles Griffin and Co. Limited London, 476pp.

Kolawole, L.B., 1981. Vertical profiles of Radio refractivity over Nigeria. Journal of West African Science Asso. 26, 41-60.

Kolawole, L.B., 1983. Statistics of radio refractivity and atmospheric attenuation in tropical climates. In: Proceedings of the URSI commission F, Belgium, pp. 69-75.

Kolawole, L.B. and Owonubi, J.J., 1982. The surface radio refractivity over Africa. Nigerian Journal of Science $16(1 \& 2), 441-454$.

Lane, J.A., 1961. The radio refractive index gradient over British Isles. Joumal of Atmospheric and Terrestrial Physics 21, 157-166.

Mctainsh, G., 1984. The nature and origin of the Aeolian mantle of Central Northern Nigeria. Geoderma, 33, 13-33.

Owolabi, I.E. and Ajayi, G.O., 1979. Super refractive conditions and their implications for trospospheric radio wave propagation in West Africa. Nig. Jour of Science, 10(1\&2), 291-307.

Owonubi, J.I., 1982. The Tropospheric radio Refractivity over Africa. M.Sc. Thesis (Unpublished), University of Ife, Ile-Ife, Nigeria.

Pickard, G.W. and Stetson, H.T., 1950. Comparison of tropospheric reception at $44.1 \mathrm{MHz}$ with $92.1 \mathrm{MHz}$ over the 167-mile path of Alpine, New Jersey to Needham, Mass, In: Proceedings of IRE 38(12), 1450.

Reitan, C.H., 1963. Surface dew point and water vapour aloft. Journal of Applied Meteorology, 2, 776-779.

Richter, J.H. (ed.), 1979. Proceedings of Conference on Atmospheric Refractive Effects Assessment. Naval Ocean Systems Center, San Diego, California. Tech. Doc. $260,167 \mathrm{pp}$.

Willoughby, A.A., Aro, T.O. and Owolabi, I.E., 1995. Incidence of super-refraction and radio ducts in the lowest layer of a tropical troposphere, In: Proc. Radio Communication in Africa. Radio Africa, 195, 145. 152.

Willoughby, A.A., Aro, T.O. and Owolabi, I.E., 2002. Seasonal variations of radio refractivity gradients in Nigeria. Journal of Atmospheric and Solar-Terrestrial Physics 64, 417-425.

Wyngaard, J.C., Nelson, S.S., Martin Otte, Xaio Di, Kenneth, E.G, 2001. Concepts, observations, and simulation of refractive index turbulence in the lower atmosphere. Radio Science, 36, 643-669.

Wyngaard, J.C. and LeMone, M.A., 1980. Behaviour of the refractive index structure parameter in the entraining convective boundary layer. J. Atmos. Sci, 37, 15731585

Yasuo, K. and Kenichi I., 1982. Single mode condition of optical fibres with axially symmetric refractive index distribution. Radio Science, 17, 1-43.

Zhamsuyeva, G.S. and Zayakhanov, A.S., 1998. Investigation of the refractive index in 100 meter lower layer of the atmosphere. In: Proceedings of the $8^{\text {in }}$ URSI commission F. Portugal. pp. 63-66. 